\title{
Nickel-Catalyzed 1,2-Diarylation of Alkenyl Ketones: A Comparative Study of Carbonyl-Directed Reaction Systems ${ }^{\dagger}$
}

Received 00th January 20xx, Accepted 00th January 20xx

\begin{abstract}
Roman Kleinmans, ${ }^{\mathrm{a}, \mathrm{c}}$ Omar Apolinar, ${ }^{\mathrm{a}, \mathrm{c}}$ Joseph Derosa, ${ }^{\mathrm{a}}$ Malkanthi K. Karunananda, ${ }^{\mathrm{a}} \mathrm{Zi}-\mathrm{Qi}$ Li, ${ }^{\text {a }}$ Van T.
\end{abstract} Tran, ${ }^{a}$ Steven R. Wisniewski, ${ }^{\mathrm{b}}$ and Keary M. Engle*a

\begin{abstract}
A conjunctive cross-coupling reaction of alkenyl ketones, aryl iodides, and arylboronic esters under nickel catalysis is reported. The reaction delivers the desired 1,2-diarylated products with moderate to excellent regiocontrol using a diverse array of ketone starting materials, as illustrated across over 40 examples. To showcase the versatility of this method, a representative product is diversified into a wide range of synthetically useful building blocks, that are not readily accessible via existing 1,2-diarylation reactions. Preliminary mechanistic studies shed light on the binding mode of the substrate, and Hammett analysis shows the effect of electronic factors on initial rates. To our knowledge, this method represents the first example of catalytic 1,2-diarylation of an alkene, directed by a native ketone functional group.
\end{abstract}

\section{Introduction}

The installation of two distinct aryl fragments across an alkene using a transition metal via conjunctive cross-coupling has recently emerged as a powerful strategy to synthesize complex molecules. ${ }^{1}$ In general, reactions of this type that involve an initial 1,2-migratory insertion step have historically required conjugated alkene substrates for reactivity and selectivity control. ${ }^{2}$ In an effort to bridge this synthetic gap, our group and others have employed directing groups to facilitate 1,2dicarbofunctionalization of non-conjugated alkenes under nickel catalysis. ${ }^{3}$ This concept was initially executed using $\mathrm{N}\left(\mathrm{sp}^{2}\right)$-containing directing auxiliaries that require at least two concession steps for installation and removal, detracting from the practicality of the approach (Scheme 1A). ${ }^{3 a-d}$ Our laboratory previously demonstrated the use of simple alkenyl amides and carboxylates in nickel-catalyzed 1,2-diarylation reactions (Scheme 1B). ${ }^{3 e, g}$ We sought to extend this reactivity to regioselective 1,2-diarylation methodology, that is compatible with native ketone functional groups, presumably binding the metal through an $\mathrm{O}\left(\mathrm{sp}^{2}\right)$ atom. ${ }^{4}$

Given the complementary utility of ketone functional groups in synthesis, we were attracted to developing chemistry with this family of substrates.5,6 At the same time, we were aware of two potential challenges:

1) the decreased Lewis basicity of the carbonyl lone pair compared to amides and carboxylates, which can impact Scheme 1. Background and Synopsis of Current Work.

\footnotetext{
a. Department of Chemistry, The Scripps Research Institute, 10550 North Torrey Pines Road, La Jolla, California 92037, United States, E-mail: keary@scripps.edu. b. Chemical Process Development Bristol Myers Squibb, One Squibb Drive, New

Brunswick, New Jersey 08903, United States

c. These authors contributed equally to this work.

+ Electronic Supplementary Information (ESI) available: CCDC 1957926. For ESI and crystallographic data in CIF or other electronic format see DOI: 10.1039/x0xx00000x
}

productive binding to the nickel catalyst in the key migratory

A. $\mathrm{N}\left(\mathrm{sp}^{2}\right)$ directing auxiliaries for $\mathrm{Ni}$-catalyzed 1,2-dicarbofunctionalization

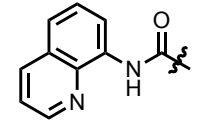

[Engle, 2017-2019]<smiles>[R]C([R])=[V]CC</smiles>

[Giri, 2017-2018]

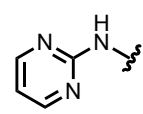

[Zhao, 2018]
B. General strategy using $\mathrm{O}\left(\mathrm{sp}^{2}\right)$ carbonyl directing groups for 1,2-diarylation

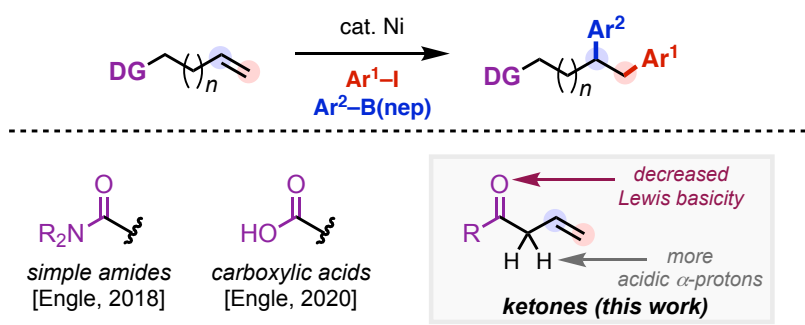

insertion step, and 2) increased acidity of the $\alpha-\mathrm{C}-\mathrm{H}$ bonds, which can lead to undesired isomerization of the alkene substrate. In a series of important previous studies, Giri has established that pre-formed ketimines can effectively engage in conjunctive cross-coupling ${ }^{7 a, b}$ and that the resulting ketimine products can be hydrolyzed to the corresponding ketones. This chemistry is limited to substrates containing unsaturation at the $\gamma, \delta$-position, presumably due to the highly acidic $\alpha$-protons that contribute to significant isomerization in the presence of organozinc nucleophiles, underscoring the difficulty of this type of transformation. Herein, we describe a selective 1,2diarylation of native ketone substrates by carefully tuning the reaction conditions (Scheme 1B). In particular, we found that through judicious tuning of solvent concentration and base, it was possible to facilitate product formation with minimal alkene isomerization.

To initiate our investigation, we elected to use aryl ketone 1 as our standard substrate, with 4-iodotoluene ( $p$-Tol-I) and phenylboronic acid neopentyl glycol ester ( $\mathrm{PhB}(\mathrm{nep}))$ as coupling partners, and 
$\mathrm{Ni}(\mathrm{cod})_{2}$ as the precatalyst with dimethyl fumarate (DMFU) as ligand 8

(Table 1).

Table 1. Optimization of Reaction Conditions. ${ }^{a}$

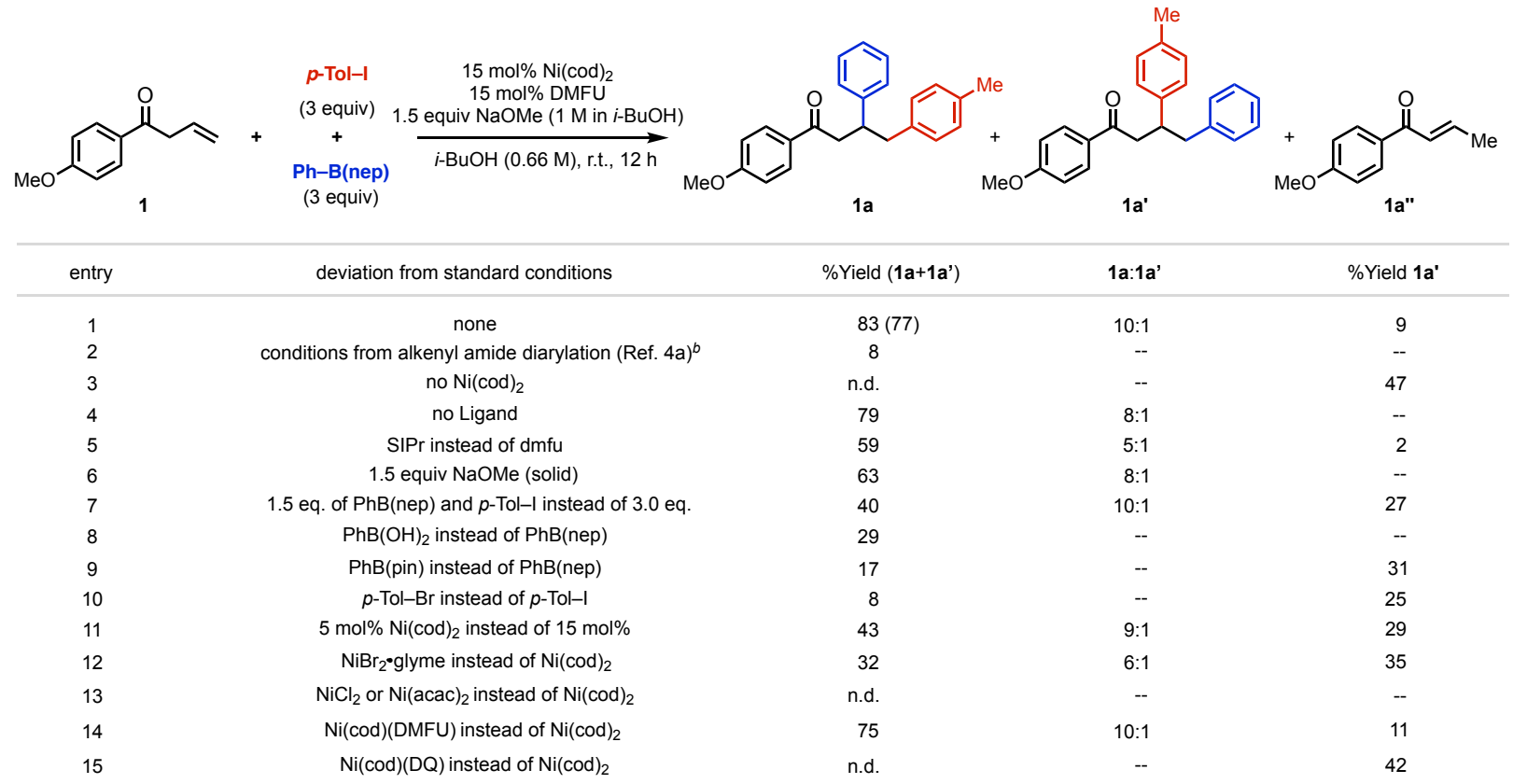

${ }^{a}$ Reactions were performed on a $0.1 \mathrm{mmol}$. Percentages represent ${ }^{1} \mathrm{H}$ NMR yields using $\mathrm{CH}_{2} \mathrm{Br}_{2}$ as internal standard; $\mathrm{n}$.d. $=$ not detected. Percentages in parentheses represent isolated yields. ${ }^{b}$ Reaction conditions: 15 mol\% Ni(cod) 2,15 mol\% DMFU, 1.5 equiv Arl, 1.5 equiv ArB(nep), 2 equiv NaOH, $0.1 \mathrm{M} i-\mathrm{BuOH}$ at r.t.

After extensive optimization and fine-tuning of reaction conditions to minimize isomerization,

Table 2. Comparison of 1,2-diarylation conditions ${ }^{a}$

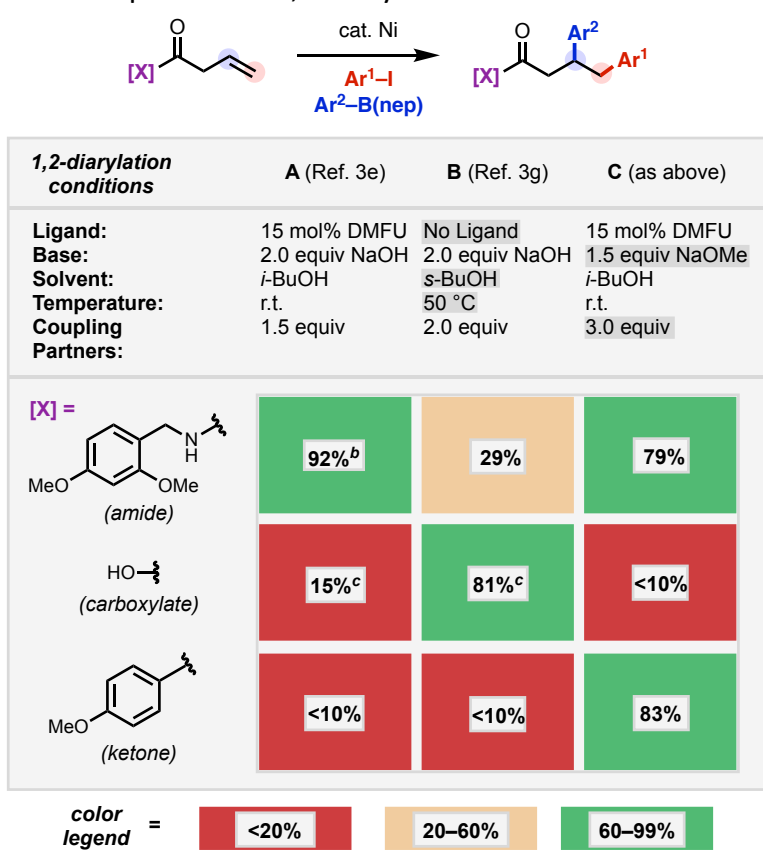

aPercentages represent ${ }^{1} \mathrm{H}$ NMR yields using $\mathrm{CH}_{2} \mathrm{Br}_{2}$ as internal standard. ${ }^{b}$ Yield taken from Ref. 3e. ${ }^{c}$ Yields taken from Ref. $3 \mathrm{~g}$.

we were able to identify conditions that delivered $83 \%$ combined yield of the two possible regioisomers in 10:1 r.r., with the major product corresponding to electrophile incorporation distal to the directing group (entry 1 ). We found the addition of NaOMe as a stock solution to be vital for high yields, presumably owing to the slow dissolution rate of the solid base (entry 6). ${ }^{9}$ Under our previously published reaction conditions for simple alkenyl amide substrates, the 1,2diarylated product(s) could be detected in only $8 \%$ yield (entry 2 ). Interestingly, the reaction proceeded in good yield without an ancillary ligand or with 1,3-bis(2,6-di-ipropylphenyl)imidazolidine-2-ylidene (SIPr) instead of DMFU, with SIPr leading to lower regioselectivity (entries 4 and 5). The corresponding free boronic acid and, the pinacol boronic ester reacted in low yields (entries 8 and 9). Encouragingly, $\mathrm{NiBr}_{2} \bullet$ glyme was a competent $\mathrm{Ni}(\mathrm{II})$ source, giving the desired products in $32 \%$ combined yield (entry 12 ). $\mathrm{NiCl}_{2}, \mathrm{Ni}$ (acac) ${ }_{2}$, and $\mathrm{Ni}(\mathrm{cod})(\mathrm{DQ})$ were found to be ineffective (entries 13 and 15). Pre-ligation of the DMFU did not offer any advantage, with the products furnished in $75 \%$ yield when $\mathrm{Ni}(\mathrm{cod})$ (DMFU) was used as the precatalyst (entries 14).

At this stage, we sought to compare the optimized conditions in each of our carbonyl-directed 1,2-diarylation reactions, to gain a better understanding of the subtle effects of changes to reaction conditions across different substrate classes (Table 2). Across all substrate classes, $\mathrm{Ni}(\mathrm{cod})_{2}$ precatalyst and alcohol solvents were necessary for obtaining high yields. In addition, the privileged reactivity of $\operatorname{ArB}(n e p)$ coupling partners, which have been shown to be superior to other boronic acid derivatives in other nickel-catalyzed reactions, is a shared feature. ${ }^{10} \mathrm{After}$ cross-screening optimized 
reaction conditions for various 1,2-diarylation reactions against amide, carboxylate, and ketone substrates, we found that choice of ligand, base, alcohol solvent, and temperature are key variables in extending this methodology to different substrate classes. For example, the amide substrate requires DMFU as a ligand to bolster the product yield, while DMFU has a minor effect with ketone substrates ${ }^{11}$ and no ligand was found to be effective in the carboxylate system. Also, less Lewis basic ketones benefited from the use of a NaOMe stock solution,

Table 3. Electrophile and Nucleophile Scope ${ }^{a}$

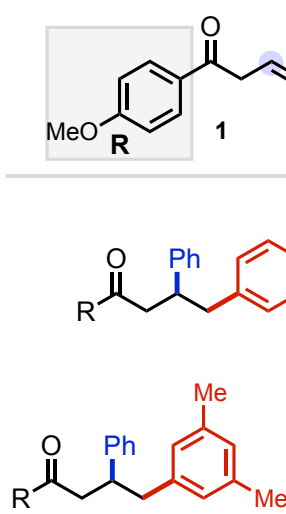

1g, $73 \%, 17: 1$ r.r.<smiles>[R]C(=O)CC(Cc1ccc(OC)cc1)c1ccccc1</smiles>

1h, $70 \%, 9: 1$ r.r. [X-ray]

$$
\begin{aligned}
& \mathrm{R}^{\prime}=\operatorname{Me}(\mathbf{1 a}), 77 \%, 10: 1 \text { r.r. } \\
& \mathrm{R}^{\prime}=\mathrm{H} \quad(\mathbf{1 b}), 77 \% \\
& \mathrm{R}^{\prime}=\mathrm{Et} \quad(\mathbf{1 c}), 67 \%, 9: 1 \text { r.r. } \\
& \mathrm{R}^{\prime}=i-\operatorname{Pr}(\mathbf{1 d}), 72 \% \text { 10:1 r.r. }
\end{aligned}
$$

compared to solid NaOMe. Both the amide and ketone substrates work well with $i-\mathrm{BuOH}$, whereas $s-\mathrm{BuOH}$ is essential to the carboxylate substrate. Interestingly, carboxylate substrates are incompatible with the optimal temperature (r.t.) for other classes, presumably owing to the elevated temperatures required to prevent inhibitory carboxylate binding. Collectively, these results illustrate the subtleties of reaction optimization across these systems, whilst providing end users with an idea of what variables to prioritize.

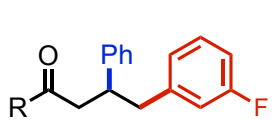

$11,48 \%, 17: 1$ r.r.

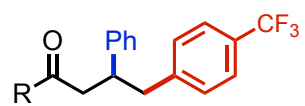

$1 \mathrm{~m}, 32 \%,>20: 1$ r.r.<smiles>[R]C(=O)CC(Cc1cc(OC)cc(OC)c1)c1ccccc1</smiles>

1i, $55 \%, 17: 1$ r.r.<smiles>[R]C(=O)CC(Cc1cccc(P)c1)c1ccccc1</smiles>

1e, $71 \%, 8: 1$ r.r.

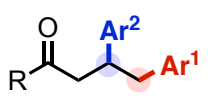

1a-z<smiles>[R]C(=O)CC(Cc1ccc2c(c1)OCO2)c1ccccc1</smiles>

1j, 64\%, 12:1 r.r.

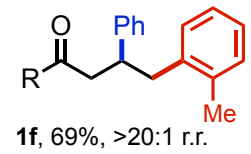

1f, $69 \%$, >20:1 r.r.

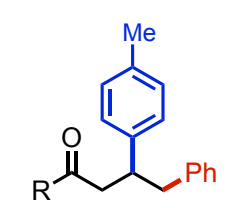

1q, $72 \%, 14: 1$ r.r.<smiles>[R]C(=O)CC(Cc1ccccc1)c1ccc(C(F)(F)F)cc1</smiles>

1v, $56 \%, 12: 1$ r.r.<smiles>[R]C(=O)CC(Cc1ccccc1)c1ccc(C(C)(C)C)cc1</smiles>

1r, 69\%, >20:1 r.r.

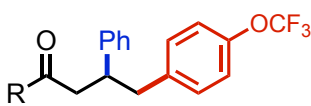

1n, $45 \%$, > $20: 1$ r.r.

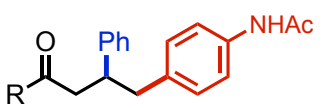

1o, $56 \%, 11: 1$ r.r.

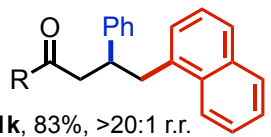

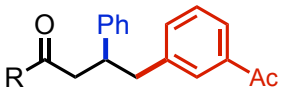

1p, $35 \%$, >20:1 r.r. nucleophile scope ${ }^{b}$<smiles>[R]C(=O)CC(Cc1ccccc1)c1cccc(C)c1</smiles>

1s, $65 \%$, >20:1 r.r.<smiles>[R]C(=O)CC(Cc1ccccc1)c1ccc(OC)cc1</smiles>

1t, $65 \%, 14: 1$ r.r.<smiles>[R]C(=O)CC(Cc1ccccc1)c1cccc(F)c1</smiles>

1u, $65 \%, 18: 1$ r.r.<smiles>[R]C(=O)CC(Cc1ccccc1)c1cc(C(F)(F)F)cc(C(F)(F)F)c1</smiles>

1w, 51\%, 14:1 r.r.<smiles>[R]C(=O)CC(Cc1ccccc1)c1ccc(Cl)cc1</smiles>

1x, 44\%, 14:1 r.r.<smiles>[R]C(=O)CC(Cc1ccccc1)c1cccc(C)c1</smiles>

1y, $72 \%,>20: 1$ r.r.<smiles>[R]C(=O)CC(Cc1ccccc1)c1ccc(CO)cc1</smiles>

1z, $70 \%, 10: 1$ r.r.

limitations (<10\%)<smiles>FC(F)(F)c1ccc(I)cn1</smiles><smiles>O=Cc1cccc(I)c1</smiles><smiles>O=[Se]C1CCCC(Br)=C1Br</smiles>

${ }^{a}$ Reactions performed on $0.1 \mathrm{mmol}$ scale. Percentages represent isolated yields. ${ }^{b}$ Reactions were performed in $i$ - $\mathrm{BuOH}(0.50 \mathrm{M})$. 


\section{Results and Discussion}

Having identified optimized reaction conditions, we moved on to examine the electrophile scope of the reaction using $\mathrm{PhB}$ (nep) as the nucleophilic coupling partner (Table 3). Aryl iodides, bearing electron-donating substituents in the para- and meta-positions, reacted in good to excellent yields to deliver the desired products with moderate to excellent regioselectivity (1a-1e, 1g-1j). Aryl iodides with substitution in the ortho-position reacted in good to excellent yields, which gave the desired products with excellent regioselectivity $(\mathbf{1 f}, \mathbf{k})$.

Electron-withdrawing substituents resulted in diminished reactivity, but still delivered the desired products in moderate yields (1) and $1 \mathrm{~m}$ ) with excellent regioselectivity. Notably, aryl iodides containing $\mathrm{Ac}$ and -NHAc groups were compatible in this reaction, allowing for potential further modification (10 and $\mathbf{1 p}$ ). It is worth mentioning, that for sterically similar electrophiles, r.r. tends to be lowest for electron-rich aryl iodides and highest for electron-poor aryl iodides. Heteroaryl iodides, 4-iodobenzaldehyde, and 4-iodophenol coupling partners were incompatible under the optimized reaction conditions. Next, we investigated the scope of the nucleophile in the reaction, using iodobenzene as the electrophilic component (Table 3). In general, a wide range of electron-rich and electron-poor ArB(nep) coupling partners performed well under optimized conditions, giving the desired products in good to excellent yield (1q1z) with moderate to excellent regioselectivity. Aryl B(nep) coupling partners containing tethered alcohols, $-\mathrm{Cl}$, and $-\mathrm{Ac}$ groups were tolerated in moderate to good yields $(\mathbf{1} \mathbf{x}-\mathbf{1 z})$. Similar to the trend observed with aryl iodide coupling partners, heterocycle-containing $B$ (nep) coupling partners were found to be incompatible at this stage of development. We next explored the scope and limitations of this method by testing other representative alkenyl ketones (Table 4). A wide range of ketone substituents were tolerated in this reaction, providing

Table 4. Ketone and Alkene Scope. ${ }^{a}$

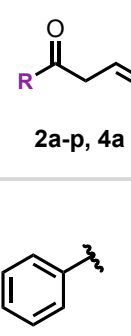

3a, $72 \%, 8: 1$ r.r.<smiles>CCNc1ccc(C(C)C)cc1</smiles>

$3 g, 62 \%, 6: 1$ r.r.<smiles>CC1CCCCC1</smiles>

$3 n, 61 \%, 8: 1$ r.r.

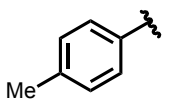

3b, $60 \%, 8: 1$ r.r.<smiles>COc1ccc(C(C)(C)C)cc1OC</smiles>

$3 h, 81 \%, 10: 1$ r.r.<smiles>CC(C)(C)c1ccc(C(C)(C)C)cc1</smiles>

3c, $63 \%, 8: 1$ r.r.

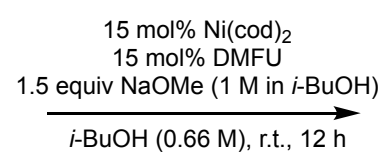

i-BuOH (0.66 M), r.t., $12 \mathrm{~h}$

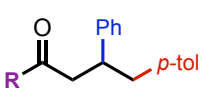

$3 a-p, 5 a$

ketone scope

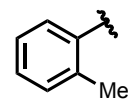

3d, $45 \%, 8: 1$ r.r.<smiles>CCc1cc(OC)ccc1F</smiles><smiles>CC(C)(C)c1cc(C(C)(C)C)cc(C(C)(C)C)c1</smiles>

3e, $77 \%, 12: 1$ r.r.

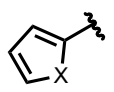

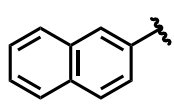

3f, $72 \%, 12: 1$ r.r.

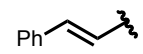

$3 \mathrm{~m}, 36 \%, 10: 1$ r.r.

$X=O(3 k), 29 \%, 14: 1$ r.r.

3i, $52 \%, 10: 1$ r.r. $\quad 3$ j, $56 \%, 11: 1$ r.r. $\quad X=S(3 \mathbf{I}), 73 \%, 12: 1$ r.r.

$3 \mathbf{j}, 56 \%, 11: 1$ r.<smiles>COCCOCC(CCC(=O)c1ccc(OC)c(OC)c1)c1ccccc1</smiles>

5 a, $60 \%, 8: 1$ r.r.

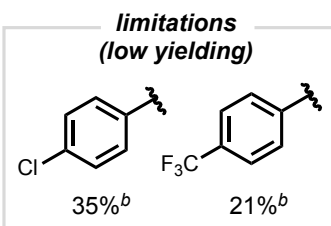

${ }^{a}$ Reactions performed on $0.1 \mathrm{mmol}$ scale. Percentages represent isolated yields. ${ }^{b}$ Percentages represent ${ }^{1} \mathrm{H} \mathrm{NMR}$ yields using $\mathrm{CH}_{2} \mathrm{Br} 2$ as internal standard. 


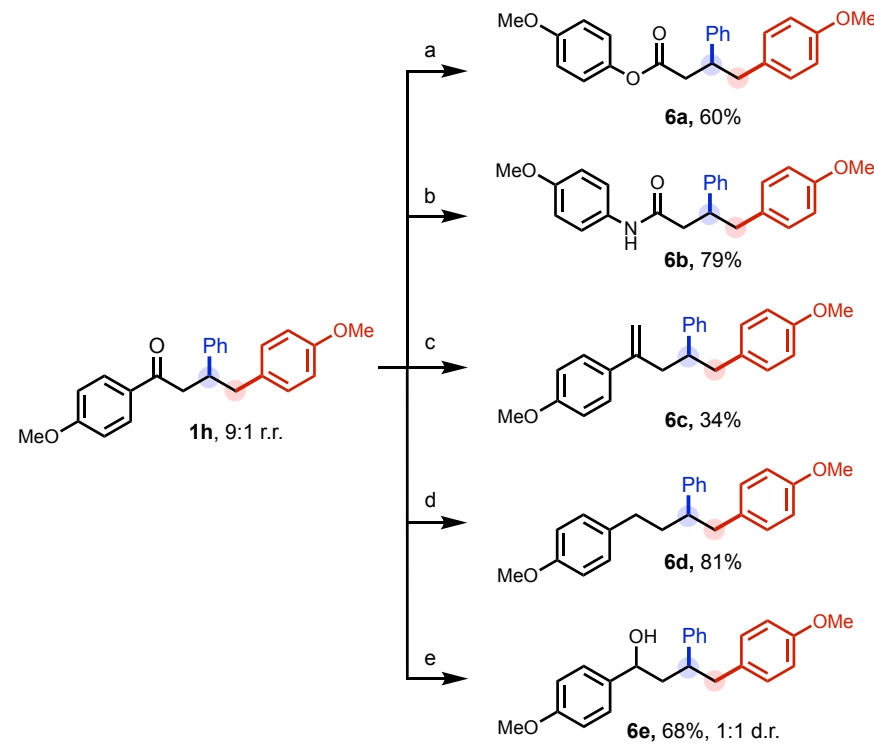

Scheme 2. Product Diversification. a) $m C P B A$, TFA, anhydrous $D C M$, r.t. b) $\mathrm{H}_{2} \mathrm{NOH} \bullet \mathrm{HCl}, \mathrm{TFA}, 70{ }^{\circ} \mathrm{C}$. c) $\mathrm{Ph}_{3} \mathrm{PCH}_{2} \mathrm{Br}, n-\mathrm{BuLi}, \mathrm{THF}, 70{ }^{\circ} \mathrm{C}$. d) $\mathrm{LiAlH}_{4}, \mathrm{AlCl}_{3}$, $\mathrm{Et}_{2} \mathrm{O} / \mathrm{DCM}$, r.t. e) $\mathrm{NaBH}_{4}$, $\mathrm{THF}$, reflux.

a general platform for the rapid assembly of $6, \gamma$-diarylated ketones in moderate to excellent yields (3a-3p), with moderate to good regioselectivity. Given the simplicity and modularity of synthesizing allyl ketones through a Barbier-allylation/oxidation sequence (see Supporting Information),

A

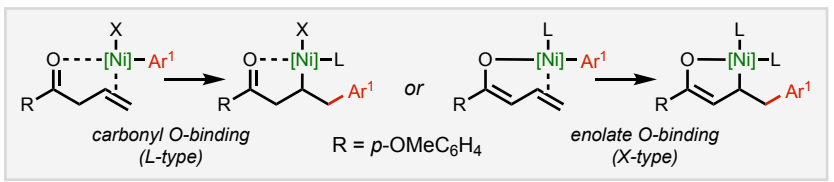

i)

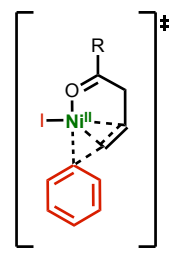

TS1

$\Delta \mathrm{G}^{\ddagger}=14.9 \mathrm{kcal} / \mathrm{mo}$ $\Delta \mathrm{H}^{\ddagger}=13.7 \mathrm{kcal} / \mathrm{mo}$

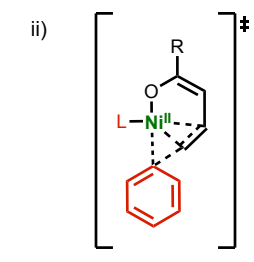

TS2 : $\mathrm{L}=i-\mathrm{BuOH}$; $\Delta \mathrm{G}^{\ddagger}=18.1 \mathrm{kcal} / \mathrm{mol}$ $\begin{aligned} \Delta \mathrm{G}^{*} & =18.1 \mathrm{kcal} / \mathrm{mol} \\ \Delta \mathrm{H}^{\ddagger} & =16.1 \mathrm{kcal} / \mathrm{mol}\end{aligned}$ $\Delta \mathrm{H}^{\ddagger}=16.1 \mathrm{kc} \mathrm{mol} \% \mathrm{Ni}(\mathrm{cod})_{2}$ $15 \mathrm{~mol} \%$ DMFU

B

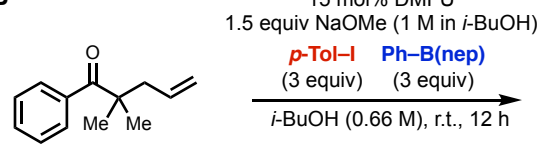

4b

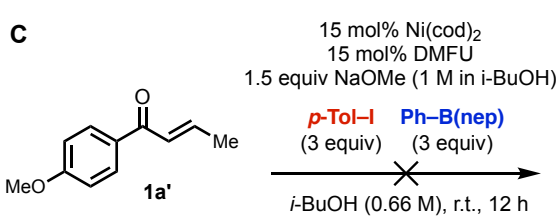

Scheme 3. Mechanistic Experiments. we anticipate that this method will serve as a powerful tool for assembling diverse building blocks for chemical synthesis. A wide range of aryl ketones with electron-donating groups were found to be compatible coupling partners, while electron-withdrawing groups on the aryl fragment led to lower yields $(\mathbf{3 a} \mathbf{3} \mathbf{3} \mathbf{j}) .^{12}$ Heterocyclecontaining ketones could be utilized (3k and $\mathbf{3} \mathbf{I}$ ) and a conjugated ketone was also tolerated (3m). Finally, alkyl-substituted ketones were suitable substrates, delivering the desired products in moderate to good yields (3n-3p). We then assessed the scope with respect to the alkenyl fragment of the substrate. Encouragingly, a $\gamma, \delta$-unsaturated ketone was a viable substrate in 1,2-diarylation (5a).

In order to showcase the versatility of this method, we subjected representative ketone product $\mathbf{1 h}$ to a series of diversification reactions (Scheme 2). Classical functional group interconversions were performed to deliver a range of synthetically useful products (6a-6e). A Baeyer-Villiger oxidation reaction provided the corresponding aryl ester in good yield (6a). Alternatively, the ketone could be converted into an amide in a single, high-yielding step via a Beckmann rearrangement (6b) andthe carbonyl group could be converted to a $\mathrm{C}=\mathrm{C}$ bond through a Wittig olefination $(6 \mathrm{c})$. The ketone directing group was removed with $\mathrm{LiAlH}_{4}$ and $\mathrm{AlCl}_{3}$ to afford $6 \mathrm{~d}$ in good yield, whilst reduction of the ketone to the corresponding secondary alcohol was obtained with $\mathrm{NaBH}_{4}$ in moderate yield, albeit with no diastereoselectivity (6e).

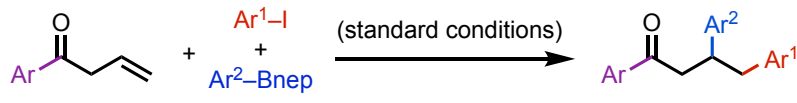

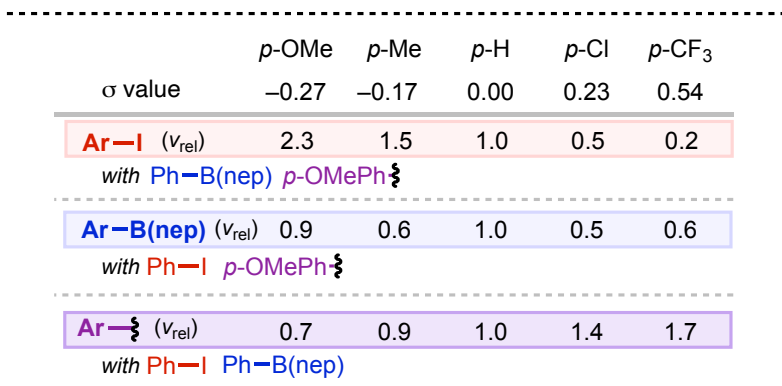

Scheme 4. Initial Rate Trends.

Next, we sought to gain insight into various mechanistic aspects of our ketone-directed 1,2-diarylation. One point of interest was the binding mode of the ketone substrate to the nickel catalyst, which could occur through the O-atom in its ketone or enolate form under basic conditions (Scheme 3A). ${ }^{7 c}$ We performed computations of the various migratory insertion transitions states with density functional theory (DFT) to gain support of the predominant mode of coordination. Upon analysis, the neutral ketone form (TS1, $\Delta \mathrm{G}^{\ddagger}=$ $14.9 \mathrm{kcal} / \mathrm{mol}$ ) is lower in energy, in comparison to both the neutral enolate $\left(\right.$ TS2, $\left.\Delta \mathrm{G}^{\ddagger}=18.1 \mathrm{kcal} / \mathrm{mol}\right)$ and anionic enolate forms (TS5, $\Delta \mathrm{G}^{\ddagger}=16.9 \mathrm{kcal} / \mathrm{mol}$ ). ${ }^{13}$ To gain further experimental support for this, we employed a ketone substrate without enolizable protons and still observed $31 \%$ yield of the de sired product, suggesting that carbonyl directivity is more likely (Scheme 3B). In a related experiment, we subjected isomerized byproduct $\mathbf{1} \mathbf{a}$ ' to the reaction conditions, which 
would be expected to react in the case of enolate directivity, given that a common dienolate would presumably be formed upon $\gamma$ deprotonation; in this case, only unreacted starting material was observed (Scheme 3C).

Next, we investigated the electronic effect of aryl iodide and boronate coupling partners with aryl ketone substrates on the rate of the reaction (see Scheme 4 and SI). Interestingly, we found very clear trends that mirror those of our previous work on simple amide substrates. ${ }^{3 e}$ While the electronic properties of the Ar-B(nep) component were negligible, electron-neutral and -rich aryl iodides reacted faster than electron-poor electrophiles. This is inconsistent with oxidative addition being turnover-limiting and points at a potential scenario in which the migratory insertion step is the turnover-limiting step. In terms of the aryl ketone electronic properties, we observe a faster rate for electron-deficient aryl ketones, despite the fact that these substrates are ultimately lowyielding. One potential explanation for this dichotomy is that electron-poor ketones succumb to off-cycle processes (e.g., isomerization) more easily, despite being inherently faster for the desired catalytic reaction. On the productive cycle, increased reaction rate with more electron-deficient carbonyl groups could indicate that the carbonyl group must dissociate during migratory insertion (and possibly re-coordinates subsequently to prevent $\beta-\mathrm{H}$ elimination) or alternatively, this could reflect increased electronic activation via inductive effects as shown in the ${ }^{13} \mathrm{C}$ resonances of the alkenyl carbon atoms across this series (see $\mathrm{SI}$ ).

\section{Conclusions}

In conclusion, we have demonstrated that a simple ketone can be used to direct nickel-catalyzed 1,2-diarylation of nonconjugated alkenes using aryl iodides and aryl boronates. These products can be further manipulated using classical methods to yield a range of valuable building blocks. Mechanistic studies support a carbonyl binding mode as opposed to enolate binding, while Hammett studies shed light on the impact of electronic factors on both the coupling partners and the substrate itself. We anticipate that the addition of ketones to the growing toolkit of native-directed 1,2difunctionalization reactions will greatly benefit the synthetic community.

\section{Conflicts of interest}

There are no conflicts to declare.

\section{Acknowledgements}

This work was financially supported by Bristol Myers Squibb and the National Science Foundation (CHE-1800280). We further acknowledge the DAAD for a PROMOS Scholarship (R. K.) and the NSF for Graduate Research Fellowships (DGE-1346837, J.D. and DGE1842471, O.A). We thank Prof. Arnold L. Rheingold for X-ray crystallographic analysis (UCSD). We thank Phillippa Cooper for detailed proofreading of the manuscript.

\section{Notes and references}

1 For representative reviews on conjunctive cross-coupling, see: (a) J. Derosa, V. T. Tran, V. A. van der Puyl and K. M. Engle, Aldrichimica Acta, 2018, 51, 21-32; (b) R. Giri and S. KC, J. Org. Chem., 2018, 83, 3013-3022; (c) J. Derosa, O. Apolinar, T. Kang, V. T. Tran and K. M. Engle., Chem. Sci., 2020, 11, 42874296; (d) H.-Y. Tu, S. Zhu, F.-L. Qing and L. Chu, Synthesis, 2020, 52, 1346-1356; (d) S. O. Badir and G. A. Molander, Chem, 2020, 6, 1327-1339; (e) X. Qi and T. Diao, ACS Catal. 2020, 10, 8542-8556.

2 (a) M. Catellani, G. P. Chiusoli and S. Concari, Tetrahedron, 1989, 45, 5263-5268; (b) K. M. Shaulis, B. L. Hoskin, J. R. Townsend, F. E. Goodson, C. D. Incarvito and A. L. Rheingold, J. Org. Chem., 2002, 67, 5860-5863; (c) K. B. Urkalan and M. S. Sigman, Angew. Chem. Int. Ed., 2009, 48, 3146-3149; (d) B. J. Stokes, L. Liao, A. M. de Andrade, Q. Wang and M. S. Sigman, Org. Lett., 2014, 16, 4666-4669; (e) Z. Kuang, K. Yang and Q. Song, Org. Chem. Front., 2017, 4, 1224-1228; (f) B. Shrestha, P. Basnet, R. K. Dhungana, S. KC, S. Thapa, J. M. Sears and R. Giri, J. Am. Chem. Soc., 2017, 139, 10653-10656; (g) P. Gao, L.-A. Chen and M. K. Brown, J. Am. Chem. Soc., 2018, 140, 10653-10657.

3 (a) J. Derosa, V. T. Tran, M. N. Boulous, J. S. Chen and K. M. Engle, J. Am. Chem. Soc., 2017, 139, 10657-10660; (b) W. Li, J. K. Boon, and Y. Zhao, Chem. Sci., 2018, 9, 600-607; (c) S. Thapa, R. K. Dhungana, R. T. Magar, B. Shrestha, S. KC and R. Giri, Chem. Sci., 2018, 9, 904-909; (d) J. Derosa, V. A. van der Puyl, V. T. Tran, M. Liu and K. M. Engle, Chem. Sci., 2018, 9, 5278-5283; (e) J. Derosa, R. Kleinmans, V. T. Tran, M. K. Karunananda, S. R. Wisniewski, M. D. Eastgate and K. M. Engle, J. Am. Chem. Soc., 2018, 140, 17878-17883; (f) V. T. Tran, Z.-Q. Li, T. J. Gallagher, J. Derosa, P. Liu and K. M. Engle, Angew. Chem. Int. Ed., 2020, 59, 7029-7034; (g) J. Derosa, T. Kang, V. T. Tran, S. R. Wisniewski, M. K. Karunananda, T. C. Jankins, K. L. Xu and K. M. Engle, Angew. Chem. Int. Ed., 2020, 59, 1201-1205; for related work with alkenyl sulfonamide substrates involving monodentate nitrogen coordination, see: (h) O. Apolinar, V. T. Tran, N. Kim, M. A. Schmidt, J. Derosa and K. M. Engle, ACS Catal., 2020, 10, 14234-14239.

4 For representative examples of radical-based metal-catalyzed approaches toward carbonyl-directed 1,2dicarbofunctionalization of alkenes, see: (a) J.-W. Gu, Q.-Q. Min, L.-C. Yu and X. Zhang, Angew. Chem. Int. Ed., 2016, 55, 12270-12274; (b) A. García-Domínguez, Z. Li, and C. Nevado, J. Am. Chem. Soc., 2017, 139, 6835-6838; (c) X. Zhao, H.-Y. Tu, L. Guo, S. Zhu, F.-L. Qing, and L. Chu, Nat. Commun., 2018, 9, 3488; (d) C. Xu, Z.-F. Yang, L. An and X. Zhang, ACS Catal., 2019, 9, 8224-8229; (e) Z.-F. Yang, C. Xu, X. Zheng and X. Zhang, Chem. Commun., 2020, 56, 2642-2645; (f) X. Wei, W. Shu, A. García-Domínguez, E. Merino and C. Nevado, j. Am. 
Chem. Soc., 2020, 142, 13515-13522; (g) H.-Y. Tu, F. Wang, L. Huo, Y. Li, S. Zhu, X. Zhao, H. Li, F.-L. Qing and L. Chu, J. Am. Chem. Soc., 2020, 142, 9604-9611 For related work involving copper catalysis, see: (h) S. Zhou, G. Zhang, L. Fu, P. Chen, Y. Li and G. Liu, Org. Lett., 2020, 22, 6299-6303.

5 For examples of carbonyl-directed two-component C-C crosscouplings, see (Pd): (a) D. L. Sandrock, L. Jean-Gérard, C. Chen, S. D. Dreher and G. A. Molander, J. Am. Chem. Soc., 2010, 132, 17108-17110; (Ni): (b) A. Wilsily, F. Tramutola, N. A. Owston and G. C. Fu, J. Am. Chem. Soc., 2012, 134, 5794-5797.

6 For a general review on ketone-directed $\mathrm{C}-\mathrm{H}$ functionalization, see: Z. Huang, H. N. Lim, F. Mo, M. C. Young and G. Dong, Chem. Soc. Rev., 2015, 44, 7764-7786.

7 (a) P. Basnet, R. K. Dhungana, S. Thapa, B. Shrestha, S. KC, J. M. Sears and R. Giri, J. Am. Chem. Soc., 2018, 140, 7782-7786; (b) P. Basnet, S. KC, R. K. Dhungana, B. Shrestha, T. J. Boyle and R. Giri, J. Am. Chem. Soc., 2018, 140, 15586-15590; (c) R. K. Dhungana, S. KC, P. Basnet, V. Aryal, L. J. Chesley and R. Giri, ACS Catal, 2019, 9, 10887-10893.

8 For a review of olefin ligands in transition metal catalysis, see: (a) J. B. Johnson and T. Rovis, Angew. Chem. Int. Ed., 2008, 47, 840-871; for examples of electron-deficient olefin ligands in nickel-catalysis, see Refs. 3e,g and the following: (b) A. E. Jensen and P. Knochel, J. Org. Chem., 2002, 67, 79-85; (c) C.Y. Huang and A. G. Doyle, J. Am. Chem. Soc., 2015, 137, 5638-5641; (d) J. G. Estrada, W. L. Williams, S. I. Ting and A. G. Doyle, J. Am. Chem. Soc., 2020, 142, 8928-8937; (d) N. Kim, V. T. Tran, O. Apolinar, S. R. Wisniewski, M. D. Eastgate, Synlett, 2021, DOI: 10.1055/a-1344-6040.

9 R. Wethman, J. Derosa, V. T. Tran, T. Kang, O. Apolinar, A. Abraham, R. Kleinmans, S. R. Wisniewski, J. R. Coombs and K. M. Engle, ACS Catal., 2021, 11, 502-508.

$10 \mathrm{ArB}$ (nep) (nep = neopentyl glycolato) nucleophiles have previously been found to perform better than other arylboronic esters, such as ArBpin compounds, in nickelcatalyzed cross-coupling reactions. For examples, see: (a) J. $\mathrm{Hu}, \mathrm{Y}$. Zhao, J. Liu, Y. Zhang and Z. Shi, Angew. Chem. Int. Ed., 2016, 55, 8718-8722; (b) R. Martin-Montero, T. Krolikowski, C. Zarate, R. Manzano and R. Martin, Synlett, 2017, 28, 26042608; (c) T. Shimasaki, Y. Konno, M. Tobisu and N. Chatani, Org.Lett., 2009, 11, 4890-4892.

11 One possible explanation for modest effect of DMFU in the present system is that the isomerized starting material may be acting as an electron-deficient olefin ligand, making the added DMFU somewhat redundant. This is further supported by the low yielding 1,2-diarylated product derived from the $\gamma, \delta$-unsaturated ketone in the absence of DMFU (see SI). Computational analysis using DFT supports this notion as well. The energy of transition state for reductive elimination is drastically lowered with the isomerized starting material than with isobutanol as the ligand (see $\mathrm{SI}$ ).

12 Although para- $\mathrm{Cl}$ and $-\mathrm{CF}_{3}$ aryl ketones gave comparable yields as examples $3 \mathrm{k}$ and $3 \mathrm{~m}$, separation issues were encountered due to the wide array of side products. The ${ }^{1} \mathrm{H}$
NMR yields are reported to show the full trend in electronics and since they were used in the initial rate experiments.

13 Computed transition states TS4 and TS5 that displayed DMFU and COD as L which were higher in energy than TS2 were excluded for simplicity and can be found in the SI. 